\title{
Mobile Health: An Efficient Service to Promote Self-care among People Introducing e-selfcare
}

\author{
Moghaddasi $\mathbf{H}^{\star}$, Sajjadi S and Tabatabaee SM \\ College of Paramedical Sciences, Shahid Beheshti University of Medical Sciences, Darband Street, Ghods, Square (Tajrish), Tehran, Iran
}

*Corresponding author: Moghaddasi H, Head of Health information Management and Medical Informatics Department, College of Paramedical Sciences, Shahid Beheshti University of Medical Sciences, Darband Street, Ghods Square (Tajrish), Tehran, Iran, Tel: +982122439982; E-mail: moghaddasi@sbmu.ac.ir

Received date: April 14, 2016; Accepted date: May 02, 2016; Published date: May 09, 2016

Copyright: (c) 2016 Moghaddasi $\mathrm{H}$, et al. This is an open-access article distributed under the terms of the Creative Commons Attribution License, which permits unrestricted use, distribution, and reproduction in any medium, provided the original author and source are credited.

\begin{abstract}
Mobile health is one of the most important electronic health services which use portable, smart devices, such as the mobile phone. With a very high rate of accessibility and a relatively low cost, this type of electronic health service can be used to offer health services to people anywhere, at any time. The main objective of the current study is to introduce the mobile health as a new service for promotion of self-care in the society. The study will continue to focus on numerous medical applications of mobile phone, particularly as an efficient and cost-effective modern device for self-care.
\end{abstract}

Keywords: Electronic health; Mobile health; Self-care; Electronic self-care (e-selfcare)

\section{Introduction}

Low quality health care can increase mortality rate which, in turn, can slow down or hinder economic growth and social welfare in different countries [1]. Electronic health, as a modern development, can promote social health, resulting in greater work efficiency, better quality of services and the return of investments [2]. Different applications of electronic health such as patient care, consultation and tele-education are considered in the strategic programs of different countries. The level of application and use of such services could indicate the level of attention paid to health issues in such countries. The World Health Organization, while enumerating the benefits of electronic health, has declared such services as one of the necessary sections in any strategic plan, in line with new developments in health services in 21 st century.

Mobile health is one of the branches in electronic health that has been under a lot of attention, while witnessing significant developments, in recent decades. Mobile health is the process of delivering health care with the help of mobile Information and communication technologies (MICT), by specifically using portable smart devices (with capabilities to integrate computational power of computers with mobile connections and present them to the user via a portable, small-size device) [3]. The usefulness of a mobile health is conditional to its success in service delivery. As such, health authorities have to adopt and carry out the sort of activities that are in line with the relevant society if they are to achieve successful administration of health services and elevation of service. Such activities should possess some particular features like their ease of access, their local availability, their cost effectiveness and the possibility of using them to treat personal health problems. With their numerous potentials, portable smart devices can bring about changes in the way health services can be offered and their noticeable changes can elevate the effectiveness of health services. Such services have notably highlighted the role of patients in taking care of their own health. Studies have indicated that patients' tele-monitoring and self-care, achievable through smart devices, are extremely useful for the management of chronic diseases [4].

According to the definition of World Health Organization [1], selfcare refers to capabilities of the individual, the family and the society in maintaining and promoting health and warding off diseases, which can be achieved with the help of specialists and even without their presence. In order to elevate the quality of self-care, health authorities should adjust changes in educational aims and health behavior at personal levels with those of the general instructions [5]. These measures indicate the importance of self-care as a new form of health behavior with great potentials to promote both personal and social health. Nonetheless, with current challenges in the way using mobile health, it seems that this omnipresent, cost-effective, care device has not been widely used to improve social health yet. To this end, this study is intended to focus on the benefits of electronic self-care (eselfcare), in an attempt to promote their wider application in different communities.

\section{Method of the Study}

As for the design of the current study, factors affecting e-selfcare and mobile health promotion in different societies were investigated. Then, the applications of mobile health in selfcare, representing the e-selfcare in three areas of health maintenance, acute disease management and chronic disease management were introduced, using relevant examples from the studies on the mobile-based software. Added to these were a number of recommendations for successful administration of eselfcare in different countries.

In line with these objectives, scholarly articles published from 2005 to 2015 were obtained through a comprehensive and detailed review of the scientifically valid publication databases like Science Direct, InterScience, ProQuest and Google Scholar. To investigate the quality of the articles in possession, they were evaluated in terms of title, abstract, introduction, research method, results, discussion and references. 


\section{Promotion of self-care via mobile health in different countries}

Self-care is the first, most important step in achieving health. It accounts for nearly 65 to 85 percent of recoveries. Self-care makes sense in all levels of health and diseases. In other words, health care covers a wide scope, beginning from self-care and extending further to include professional care for acute diseases. The level of self-care depends on the health condition of the individual and factors influencing people's education and life experience [6]; the care is of special importance regardless of people's political or geographical diversity. However, the most important factor in achieving proper selfcare in different societies is the initiation of change in people's life style which can be achieved via education which normally entails behavioural changes [7]. Through education and with the help of information technology, health authorities can elevate public information in areas dealing with self-care, while boosting people's motivation toward the implementation of such care. The provision of suitable educational tools will increase the quality and effectiveness of self-care [8].

Smart mobile phones deal with daily life of many individuals, with many people currently using them. So, they can be used to develop an effective network of care [9]. Currently, a rapid increase in the number of mobile phones and the services that they offer, together with their continuous developments worldwide, even in rural areas, have provided an opportunity for health authorities to promote their application in extending care, particularly among the middle or low income countries [10]. Numerous studies have shown that mobile phones can provide effective health care services in developing countries. 64 per cent of all mobile phone users are based in developing countries, which is an important factor in developing eselfcare as a branch of mobile health. The services that the phones offer are extremely dynamic, with a constantly developing planning scope. The expected long-term goal can be the provision of the right condition for mobile programs in order to have a positive effect on treatment outcome by decreasing mortality rate, increasing longevity and reducing diseases [11].

Nonetheless, it is necessary to refer to this point that the implementation of mobile health varies from region to region and country to country, and that the health systems all over the world should offer mobile services based on needs and requests arising from such varieties $[6,12]$. An increase in life standards, compared to the past, on the one hand, and changes in people's life style in different parts of the world, on the other, have greatly influenced health challenges worldwide. Hence, it is necessary to pay attention to the meaning of public and personal health, nutrition, life style and environmental, sociocultural and economic conditions of people in planning for their health [7]. In general, for successful administration of mobile health services for self-care purposes, the care system of a country should consider social, organizational and cultural features, together with challenges such as people's health and technology knowledge in order to be able to properly identify the level and scope of the services that could be offered to the affiliated people.

Mobile health can be more effective if it possesses features like ease of access, availability of local services, solutions for personal health problems and cost effectiveness [10]. To this end, mobile health should consider specific social, ethical and demographic groups when getting organized; besides, cultural resources should be paid attention to, when planning for the services. Meanwhile, the objectives behind the services that are to be offered should be measurable to enable the health authorities to evaluate the quality and effectiveness such services in future and, accordingly, removes any possible deficiencies. Good cooperation and proper coordination between different organizations in offering such services could be very useful as they can help health authorities to elevate the efficiency of services.

\section{Enhancing self-care via mobile health}

In recent years, the application of mobile processors, such as PDA (Personal Digital Assistant), in the field of health has been very common. Smart mobile phones are the most widely used devices that are commonly used for short messages, phone calls, the internet, wireless systems, health software and video links. As such, the results from previous studies show that three strategies are used to achieve self-care objectives [13]. The first strategy is the maintenance of health which is intended to avoid numerous afflictions such as early death, accident-related handicaps, psychological illnesses, behavioural problems and heart discomforts. Reduction in such illnesses would definitely depend on elevation of people's knowledge and changes in their health behaviour. The second important mobile-related, self-care strategy deals with chronic illnesses which form the main challenge of the health system in different countries in the 21 st century. Today the epidemics of non-contagious illnesses accounts for $60 \%$ of mortalities of the world [1]. Offering care to those with chronic illnesses, in an attempt to cope with the growing number of such ailments; form a key priority for the health sector. In this regard, the elevation of self-care is an essential undertaking $[1,13]$. The third strategy for self-care achievement is the application of mobile for acute illnesses. With the development of self-care services, depending on the health status of the society and factors that can contribute to people's education, health authorities should provide people with different mobile health facilities, including support systems and information packages; this could be in line with suitably planned health service policies; as such, the proper flow of information should also be safeguarded anywhere and at any time [13].

The role of environment in adopting self-care behaviour is inevitable; it may even be the most important factor because social factors could play a very significant role in achieving self-care. Therefore, the services offered in different societies should not necessarily be the same; rather, they should be identified based on the particular condition of the affiliated society [7-8].

For example, a country like Afghanistan, marking the lowest-rank in developing countries, with unique socio-cultural features and limited public knowledge about health and information technology, eselfcare can use the mobile to communicate with health care centres to receive consultation services.

In a country like Iran, with a better position in developing countries, prevention-based e-self-care infrastructures have not been adequately provided by its Ministry of Health. The medical community in this country also focuses on a treatment-based approach. On the other hand, despite the high rate of smart phone use among the public, a significant number of people have limited knowledge about information and communication technologies in Iran. Hence, in such condition, e-selfcare is inevitably limited to basic health care software and simple educational applications with limited functions like calculation of vital signs and calories consumption.

In developed countries like the USA, Britain and most European countries, due to the availability of the infrastructure needed for the implementation of e-selfcare, and a social tendency toward the 
technologies, most people have reasonable knowledge about health and ICT, which could serve as a sound basis for successful implementation of e-selfcare in three areas of Health maintenance, acute disease management and chronic disease management.

Indeed, mobile health services for self-care have to be performed based on the following factors:

The provision of quick replies to medical care users, regardless of the geographical location.

The provision of medical consultations and communications via images and video facilities.

The development of a robust infra-structure, with suitable facilities, for information technology and communications [13].

The applications of health services in three different areas of selfcare, including health maintenance, management of chronic; and acute diseases, have resulted in significant health gains. What follows is a brief account of such gains, which can be used as practical evidence for further development of numerous self-care devices, particularly the mobile health.

\section{Self-care for health maintenance}

Using short messages and mobile-oriented applied programs to initiate motivation and encourage self-care use for people.

Outcome: Mobile care will encourage children and adults toward nutritional care and physical activities [14].

Using mobile-based software to manage infants' health condition and to offer care consultations to mothers.

Outcome: Mothers would be fully satisfied with the services offered to take care of their newborns [15].

Using short messages and receiving information on weight reduction in three months in an attempt to help the individuals reduce weight.

Outcome: The weight reduction would happen faster among the message recipients [16].

Using short messages or direct phone calls via the cell phone about the babies' diet and their skin care, to achieve better pre-natal and postnatal care.

Outcome: Mothers would pay more attention to self-care to improve their baby's health [17].

\section{Self-care in chronic diseases}

Designing and using renal Trkrr software in an attempt to deliver a proper dieting program to help the kidneys function better and to communicate with specialists.

Outcome: Patients' self-care would improve [18].

Application of smart mobile phones for a distant dialogue with the physician for injury-related cares, to take care of the patient and to organize and interpret patient information.

Outcome: Smart mobile was shown to be appropriate and efficient and could be used for self-care purposes [19].
Using video messages about diabetes and their relevant care in order to enhance diabetic patients' self-care awareness on the level of blood hemoglobin and glucose.

Outcome: The messages could cause a noticeable improvement in patients' self-care [20].

Designing and using a life-phone software for diabetic patients and those with kidney problems or artificial pancreas.

Outcome: The software would result in patient satisfaction for offering cost-effective, high quality services [21].

Designing and using the Diabeo software in smart cell phones to predict the consumption of carbohydrates, level of blood glucose, and patient's physical activity.

Outcome: The software proves to be noticeably effective in improving metabolic control, at low cost and no need for physician referral [22].

\section{Self-care in acute diseases}

Designing and using mobile-based software to offer ECG care and to control the heart beat in patients that have recently experienced a heart stroke.

Outcome: Mobile health has manifested a significant effect in managing patient's heart beats and ECG. It has also caused a reduction in re-emergence of the illness, while resulting in a noticeable decrease in the costs for hospital care. More importantly, it alleviates the problems caused by shortages in facilities and medical staff [23].

\section{Conclusion}

The need for further development of information technology in the field of health is warranted by numerous reasons as follows: quick access to patients' history, distant doctor-patient consultations, better treatment outcomes, greater respect to clients, better services for patients and more effective information exchange to promote social health. Considering the fact that mobile phone is used by nearly everybody nowadays, and that nearly all people, even those in remote areas, without proper access to health facilities, use a cell phone, its further development in health field will significantly promote medical services offered to people, resulting in people's awareness of self-care and personal health. Proper nutritional program, regular exercise, sufficient rest, low level of anxiety and stress and greater incentive and enthusiasm are among the factors that could lead to better social health and more effective management of opportunities. Following such health friendly issues, and adopting health promoting activities, while avoiding health-harming deeds, are all at the stake of patient's knowledge, skill and commitment to take part in his/her own treatment and self-care. As such, by providing more education and promoting the application of information technology, particularly mobile phones, health authorities can help people to enhance their knowledge of self-care, with greater incentive to use such devices. Of course, further development of such services, as indicated above, would require people's greater familiarity with information technology and health issues in order to be able to use such technology. They should be able to make the necessary decisions for their family members and themselves in their personal life and under critical conditions. To this end, the arrangement of classes, workshops and radio and television programs can be highly effective. 
Citation: Moghaddasi H, Sajjadi S, Tabatabaee SM (2016) Mobile Health: An Efficient Service to Promote Self-care among People Introducing eselfcare. J Health Med Inform 7: 223. doi:10.4172/2157-7420.1000223

Page 4 of 4

\section{References}

1. World Health Organization (2013) Global tuberculosis control: surveillance, planning, financing: WHO report 2008.

2. Grieger DL, Cohen SH, Krusch DA (2007) A pilot study to document the return on investment for implementing an ambulatory electronic health record at an academic medical center. J Am Coll Surg 205: 89-96.

3. Free C, Phillips G, Felix L, Galli L, Patel V, et al. (2010) The effectiveness of M-health technologies for improving health and health services: a systematic review protocol. BMC Res Notes 3: 250.

4. Webber D, Guo Z, Mann S (2013) Self-care in health: we can define it, but should we also measure it? Self Care 4: 101-106.

5. Ministry of Health (2015) Treatment and Medical Education, Department of Health, Health Promotion and Education Office, The triangle of self-care, Information package component for enabling people to self-care pp: 2-8.

6. Kickbusch I (1989) Self-care in health promotion. Soc Sci Med 29: 125-130.

7. Ministry of Health (2015) Treatment and Medical Education Department of Health, Health Promotion and Education Office, A healthy life through self-care, "self-care" information package pp: 2-5.

8. Ministry of Health (2015) Treatment and Medical Education, Department of Health, Health Promotion and Education Office, self-care; expression on empowerment of people's health (2). Self-care and public information package pp: 2-4.

9. Fiordelli M, Diviani N, Schulz PJ (2013) Mapping mHealth research: a decade of evolution. J Med Internet Res 15: e95.

10. van Velthoven MH, Li Y, Wang W, Du X, Wu Q, et al. (2013) mHealth Series: mHealth project in Zhao County, rural China - Description of objectives, field site and methods. J Glob Health 3: 020401.

11. Hewapathirana R (2010) m-Health: Evidence and Best Practices. Journal of Bio-Medical Informatics 1: 120-123.

12. Moghaddasi H, Asadi F, Hosseini A, Ebnehoseini Z (2012) E-Health: a global approach with extensive semantic variation. J Med Syst 36: 3173-3176.

13. Burney SMA, Nadeem M, Zain A (2010) Information and Communication Technology in Healthcare Management Systems:
Prospects for Developing countries. International Journal of Computer and Applications 4: 1.

14. Tate EB, Metz DS, O’Reilly G, Marsh MJ, Gotsis M, et al. (2013) mHealth approaches to child obesity prevention: successes, unique challenges, and next directions. Translational Behavioral Medicine 3: 406-415.

15. Kuo MC, Lu YC, Chang P (2012) A Newborn Baby Care Support App and System for mHealth. NI 2012 (2012) 2012: 228.

16. Shaw RJ, Bosworth HB, Silva SS, Lipkus IM, Davis LL, et al. (2013) Mobile health messages help sustain recent weight loss. Am J Med 126: 1002-1009.

17. Cormick G, Kim NA, Rodgers A, Gibbons L, Buekens PM, et al. (2012) Interest of pregnant women in the use of SMS (short message service) text messages for the improvement of perinatal and postnatal care. Reprod Health 9: 9.

18. Touchard G, Bridoux F (2013) C3 glomerulopathy in adults: monoclonal gammopathy should be considered. Am J Kidney Dis 61: 644 .

19. Friesen MR, Hamel C, McLeod RD (2013) A mHealth application for chronic wound care: findings of a user trial. Int J Environ Res Public Health 10: 6199-6214.

20. Bell AM, Fonda SJ, Walker S, Schmidt V, Vigersky RA (2012) Mobile Phone-Based Video Messages for Diabetes Self-Care Support. Journal of Diabetes Science and Technology 6: 310-319

21. Capozzi D, Lanzola G (2011) Utilizing Information Technologies for Lifelong Monitoring in Diabetes Patients. Journal of Diabetes Science and Technology 5: 55-62

22. Charpentier G, Benhamou PY, Dardari D, Clergeot A, Franc S (2011) The Diabeo Software Enabling Individualized Insulin Dose Adjustments Combined With Telemedicine Support Improves HbAlc in Poorly Controlled Type 1 Diabetic Patients: a 6-month, randomized, open-label, parallel-group, multicenter trial (TeleDiab 1 Study). Diabetes Care 34: 533-539.

23. Dubey D, Amritphale A, Sawhney A, Amritphale N, Dubey P, et al. (2014) Smart phone applications as a source of information on stroke. J Stroke 16: 86-90. 